\title{
DA GERAÇÃO ESPONTÂNEA À QUÍMICA PREBIÓTICA
}

\author{
Dimas A. M. Zaia \\ Departamento de Química, Centro de Ciências Exatas, Universidade Estadual de Londrina, CP 6001, 86051-990 Londrina - PR
}

Recebido em 27/3/02; aceito em 7/8/02

\begin{abstract}
FROM SPONTANEOUS GENERATION TO PREBIOTIC CHEMISTRY. In the present paper, a historical view from spontaneous generation of life to Oparin-Haldane hypothesis was discussed. It was also showed what is the main concern of the field of prebiotic chemistry. Several aspects of prebiotic chemistry such as synthesis of biomolecules and biopolymers, primitive metabolism and genetic code, and the importance of the adsorption for the origin of life were discussed.
\end{abstract}

Keywords: prebiotic chemistry; Oparin-Haldane; spontaneous generation.

\section{INTRODUÇÃO}

O homem olha à sua volta e tenta explicar o mundo que o cerca, desde tempos imemoriais. As explicações são dos mais variados tipos, porém todas tentativas. Algumas perguntas sempre fizeram e ainda fazem parte das diversas culturas e gerações que existiram. Quem já não se fez pelo menos uma vez na vida algumas destas perguntas: como surgiram todas as coisas, as estrelas, os planetas, o nosso planeta, o Universo? Como era antes disto tudo existir? Como surgiram os peixes, os pássaros, os animais e nós os homens? De onde veio a vida? Para onde vai tudo isto? Talvez as perguntas mais freqüentes sejam: de onde venho e para onde vou? Qual é razão disto tudo? Diferentes culturas, diferentes gerações produziram diferentes explicações para algumas das questões acima citadas. A Ciência, ao longo dos séculos vem tentado responder algumas dessas perguntas. Neste artigo discutimos o problema da origem da vida desde da teoria da geração espontânea até presente momento e como a Ciência tem procurado resposta à pergunta "Como surgiu a vida na Terra?"

\section{A TEORIA DA GERAÇÃO ESPONTÂNEA}

O problema de origem da vida, na realidade, não era assunto que preocupava a comunidade científica até o início do século XIX, pois todos acreditavam que era possível obter seres vivos a partir de matéria inanimada, ou seja, pela geração espontânea. Muitos filósofos, cientistas, pensadores e mesmo qualquer pessoa culta aceitavam a existência de duas maneiras de gerar um ser vivo: através dos seus semelhantes (pais) e por geração espontânea. Esta ampla aceitação da geração espontânea pode parecer muito estranha para nós homens dos séculos XX e XXI, no entanto, eminentes pensadores, tais como Thales, Platão, Epicuro, Demócrito, São Tomás de Aquino, Paracelso, Goethe, Copérnico, Galileu, Harvey, Francis Bacon, Descartes, para citar somente alguns, não tiveram nenhum problema de ordem filosófica ou científica em aceitar a geração espontânea de seres vivos. Existiram verdadeiras "receitas" para produzir os mais diferentes tipos de seres vivos, desde pequenos insetos e vermes até crocodilos, "recomendando-se" a utilização de matéria orgânica em estado de putrefação. Uma destas receitas foi proposta pelo médico Johann Baptista van Helmont que, apesar de ter realizado um impor-

e-mail: zaiazaia@sercomtel.com.br tante estudo sobre a nutrição de plantas, conduziu o seguinte experimento para a produção de camundongos. A "receita": num jarro, colocar algumas roupas de baixo suadas e depois cobrir com trigo, após 21 dias ocorre a geração de camundongos adultos e totalmente formados. É obvio para nós que van Helmont não realizou um experimento controlado, pois o frasco permaneceu aberto o que possibilitou a entrada desses animais para se alimentarem com o trigo e procriarem, no entanto, isto passou despercebido pelas grandes mentes científicas daquela época. A teoria da geração espontânea só começou a perder sua credibilidade quando o médico Francesco Redi realizou o seguinte experimento (este experimento não era novidade, outros já o haviam realizado): colocou numa caixa aberta a carne de uma cobra recentemente morta, após alguns dias observou algumas larvas, na carne em putrefação, que posteriormente se transformaram em ovos e por último em moscas. Redi não parou por aí. Ele pegou novamente carne fresca de cobra e a separou em duas porções. Uma das porções colocou dentro de uma caixa aberta e a outra enrolou num pedaço de pano, colocou dentro de uma caixa e posteriormente cobriu esta caixa com um pano. Na caixa aberta obteve os mesmos resultados anteriores e na caixa fechada não observou larvas ou ovos. Assim, Redi concluiu que na caixa aberta, as moscas depositavam seus ovos na carne da cobra e estes se transformaram em larvas e que na caixa fechada com o pano, a carne de cobra ficou protegida das moscas e por isto não foram observadas as larvas. Este experimento apesar de ser muito simples deu um duro golpe nos defensores da teoria da geração espontânea, mas não desencorajou alguns de seus ferrenhos defensores. Por volta da metade do século XVIII, o padre jesuíta e naturalista John Turberville Needham realizou diversos experimentos com diversos tipos de extratos, colocando-os em frascos de vidros que eram submetidos à ebulição por alguns minutos; após isto, alguns frascos eram lacrados hermeticamente e outros eram simplesmente tampados com rolhas; entretanto, após alguns dias Needham observou que em todos os casos havia uma grande quantidade de microorganismos. O experimento de Needham tinha uma falha, pois antes dos frascos serem lacrados, ar contaminado entrava nos mesmos fazendo com que algum tempo depois fossem observados os microorganismos. Isto reacendeu a questão e deu um novo alento aos defensores da teoria da geração espontânea, que passaram a defender que, em princípio, microorganismos poderiam ser produzidos a partir de matéria inanimada. Até meados do século XIX a comunidade científica estava dividida nesta questão. Este dilema só foi resolvido com os clássicos experimentos realizados por Louis Pasteur e John Tyndall, sendo que este 
último demonstrou que algumas bactérias eram resistentes ao calor e poderiam depois de algum tempo voltar a se reproduzir permitindo, assim, explicar algumas observações que a primeira vista pareciam corroborar a teoria da geração espontânea. Portanto, a partir destes experimentos a teoria de geração espontânea foi totalmente abandonada pelos cientistas $^{1,2}$.

\section{A HIPÓTESE DE OPARIN-HALDANE}

Depois dos experimentos de Pasteur, transcorreram mais de 60 anos até que a comunidade científica voltasse a discutir o problema da origem da vida. Uma das razões desta demora foi que, com o passar dos anos, uma enorme quantidade de informações a respeito da morfologia e das reações que ocorrem no interior da célula revelou a sua grande complexidade, mesmo em se tratando de uma simples bactéria. Isto fez crescer na comunidade científica a sensação de que a questão "como se iniciou a vida" não era passível de estudo, pois a célula era muito complexa. Por outro lado, o desenvolvimento científico e tecnológico, ocorrido principalmente na geologia e na astronomia, que passou a estudar a composição química das estrelas pela espectroscopia, desencadeou discussões na comunidade científica, sobre a idade da Terra e do Sistema Solar e como estes foram formados. Portanto, a combinação dos fatos de que a Terra era muito antiga e que uma competição entre moléculas (darwinismo molecular) poderia ter ocorrido até o surgimento do primeiro ser vivo levou muitos cientistas a começar a pensar que em princípio os experimentos de Pasteur não excluíam a possibilidade da geração de organismos vivos a partir de matéria inanimada, porém era óbvio que isto não poderia ocorrer num tempo tão curto, como defendiam os adeptos da geração espontânea. Darwin foi o primeiro a escrever uma proposta que a vida poderia ter surgido da matéria inanimada, através do aumento da complexidade das substâncias formadas através de reações químicas. Porém, não despendeu tempo desenvolvendo tais idéias ou mesmo divulgando-as. O bioquímico russo A. I. Oparin, em 1924, foi o primeiro a desenvolver e divulgar que a vida poderia ter surgido em nosso planeta a partir de matéria inanimada, utilizando-se de um esquema semelhante ao de Darwin, porém muito mais elaborado. Posteriormente, em 1929, independentemente de Oparin, o geneticista inglês J. B. S. Haldane propôs um esquema semelhante de origem da vida. Atualmente, esta proposta é conhecida como hipótese de OparinHaldane. Podemos colocá-la de forma resumida da seguinte maneira: primeiramente, a partir de moléculas simples (por exemplo metano, amônia, água, hidrogênio) que reagiam entre si, ocorreu o acúmulo de biomoléculas (aminoácidos, lipídios, açúcares, purinas, pirimidinas etc.), isto levou um período de muitos milhões de anos; posteriormente, estas biomoléculas começaram combinar umas com as outras para formar biopolímeros (moléculas gigantescas feitas pela repetição de unidades simples, como por exemplo as proteínas, que são sintetizadas a partir das unidades aminoácidos); mais alguns milhões de anos transcorreram e, então, estes biopolímeros começaram a se combinar formando o que Oparin chamou de estruturas coacervadas, que lembram muito as células de hoje. Com o passar dos anos (milhões deles), no interior destas estruturas coacervadas, reações cada vez mais complexas continuaram a acontecer até podermos dizer que tivemos a primeira coisa viva. Aqui definimos um organismo vivo como sendo aquele que usa substâncias do meio ambiente para retirar energia (metabolismo), gerar semelhantes (reprodução) e poder mudar (evoluir). No entanto, devemos deixar claro que existem muitas definições do que é um ser vivo, a que adotamos é apenas uma delas, sendo que não há na comunidade científica um consenso sobre este assunto. Luisi ${ }^{3}$ discute detalhadamente definições de um ser vivo dadas por Bernal, Oparin, Engels, NASA, Pirie, entre outros. A partir deste ponto, adotamos a teoria da evolução de Darwin dentre outras que existem para poder- mos explicar a grande diversidade de vida atualmente encontrada em nosso planeta. O esquema de etapas para a origem da vida, desenvolvido por Oparin-Haldane, forneceu um método para estudar a questão, ou seja, podemos em laboratório reproduzir algumas daquelas etapas e, com isto, reconstruir todos os passos para a formação de um ser vivo ${ }^{1-6}$.

A hipótese de Oparin-Haldane tenta explicar como ocorreu o início da vida em nosso planeta e abre a possibilidade da existência de vida em algum outro planeta além do nosso. Este assunto, outros mundos habitados, não é recente e, na verdade, a possibilidade da existência de outros mundos habitados vem sendo defendida através dos tempos por diversos pensadores e cientistas, como por exemplo, Leucipo (500 A.C.) e Epicuro (341-270 A.C.); Giordano Bruno (1548-1600); J. Kepler (1571-1630, astrônomo alemão), Galileo Galilei (1564-1642, cientista italiano), Christian Huygens (16291695, físico e astrônomo holandês) e Immanuel Kant (1724-1804, filósofo alemão), dentre outros. Outra questão menos evidente na hipótese de Oparin-Haldane é a possibilidade de termos o Universo cheio de formas de vida, isto se nenhuma das etapas de todo o processo de criação do ser vivo for extremamente rara de acontecer. Assim, teremos um Universo cheio de vida se tivermos em muitos lugares (outros planetas em outros sistemas solares) as condições adequadas, tanto para o início da formação das moléculas essenciais, como para todas as etapas subseqüentes ${ }^{2,3,6}$.

Algumas questões ainda surgem com relação à hipótese de Oparin-Haldane: é correta a hipótese de Oparin-Haldane? Alguém conseguiu produzir um ser vivo em laboratório a partir de matéria inanimada? Quanto à primeira pergunta podemos dizer que existem muitas evidências experimentais a favor da hipótese de OparinHaldane, mas quanto à segunda pergunta, a resposta é não ${ }^{7}$.

Como existem muitas evidências de que, em princípio, a hipótese de Oparin-Haldane seja correta, então podemos supor que vivemos num Universo cheio de vida! Uma boa parcela da comunidade científica tem, nos últimos 30 anos, se dedicado para tentar responder a esta pergunta, contudo a questão não é simples, alguns aspectos envolvidos neste problema foram discutidos em artigo de divulgação científica abordando a vasta literatura existente ${ }^{7}$.

\section{A QUÍMICA PREBIÓTICA}

O clássico experimento de Miller ${ }^{8}$ foi a primeira evidência experimental que a hipótese de Oparin-Haldane poderia estar correta. Miller ${ }^{8}$ fez o seguinte experimento: a mistura dos gases metano, amônia e hidrogênio simularia a atmosfera primitiva, os eletródios gerariam faíscas que simulariam os raios e seriam fonte de energia para as reações, e o frasco com água simularia o mar (Figura 1). Após algumas semanas de reação o frasco com água apresentava uma coloração vermelha e compostos de coloração amarela. Uma análise química da solução aquosa mostrou a existência dos aminoácidos glicina, $\alpha$-alanina, $\beta$-alanina, ácido aspártico e $\alpha$ aminoácido-n-butírico. Já que aminoácidos são os blocos construtores das proteínas, este experimento mostrou que uma mistura simples de gases foi capaz de gerar algumas moléculas essenciais a todos os seres vivos conhecidos. Portanto, podemos dizer que Miller iniciou o que hoje chamamos de Química Prebiótica.

A Química Prebiótica estuda as reações químicas que poderiam ter contribuído para o surgimento da vida em nosso planeta. Portanto, nesta área do conhecimento estamos interessados em qualquer reação que, em princípio, possa levar à formação de alguma molécula que seja hoje vital para os seres vivos (aminoácidos, vitaminas, lipídios etc.), ou precursores desta (dímeros de cianetos), ou biopolímeros (proteínas, peptídeos, glicogênio, DNA etc.) ou estruturas coacervadas que possam ser geradas de diversas maneiras 


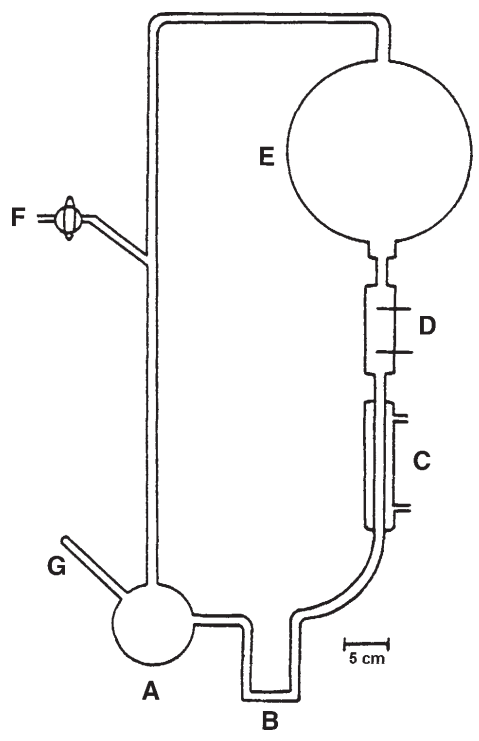

Figura 1. Aparelho utilizado por Miller para a síntese de aminoácidos: $\mathbf{A}$ frasco com água aquecido a $80{ }^{\circ} \mathrm{C} ; \boldsymbol{B}$-tubo em $U$ para evitar a circulação dos gases na direção oposta; $\boldsymbol{C}$-condensador; $\boldsymbol{D}$-eletrodos; $\boldsymbol{E}$-balão de $5 \mathrm{~L}$ onde foram adicionados os gases (metano, amônia e hidrogênio); $\boldsymbol{F}$-torneira ligada ao sistema de vácuo para fazer os gases circularem; $\boldsymbol{G}$-torneira para retirada de amostras

(aminoácidos, lipídios, aminoácidos mais silicatos, açúcares etc.), ou um metabolismo primitivo, ou um código genético, assim por diante. No entanto, todas estas reações têm que ser realizadas em condições tais que um dia possam ter existido ou ainda existam na Terra. Portanto, os dados geoquímicos e geológicos de composição da Terra, desde sua formação até o presente momento, são indispensáveis para selecionar os possíveis ambientes (condições de reação), em todas as reações que serão estudadas ${ }^{1}$. Por outro lado, o tema não é tão simples como pode parecer, pois na comunidade científica atualmente não há um consenso sobre muitas coisas, tais como quais eram as condições iniciais para a formação das biomoléculas, como foi o primeiro metabolismo e código genético, e assim por diante.

Experimentos do tipo realizado por Miller passaram a ser muito questionados pois, segundo os geoquímicos, a atmosfera terrestre jamais foi redutora, ou seja, formada por gases em suas formas mais reduzidas $\left(\mathrm{CH}_{4}, \mathrm{NH}_{3}\right)$ mas sim, na melhor das hipóteses, mais ou menos redutora $\left(\mathrm{CO}, \mathrm{H}_{2}, \mathrm{~N}_{2}\right)$ e neste tipo de atmosfera o rendimento de aminoácidos produzidos era muito baixo ${ }^{9}$. No entanto, utilizando condições de maior energia algumas moléculas importantes podem ser sintetizadas, como aminoácidos, guanina, uracil e citosina, dentre outras ${ }^{10}$.

Reações em estado sólido mostraram-se propícias para a formação de peptídeos e proteínas, quando misturas de aminoácidos eram aquecidas com areia, pois tal reação facilitava a liberação da água para a formação da ligação peptídica ${ }^{11}$. Algumas outras reações que ocorrem no estado sólido podem ter sido importantes ${ }^{12}$. Porém, é óbvio que nem todas as etapas para a formação de um ser vivo podem ter ocorrido em estado sólido, visto que em todos os seres vivos que conhecemos suas reações químicas ocorrem em meio aquoso.

Desde a descoberta de fontes geotérmicas em lugares profundos nos oceanos, devido a vulcanismo, este tipo de ambiente tem sido muito estudado. As altas temperaturas e elevadas pressões fazem com que as propriedades físicas da água sejam alteradas e esta passe a se comportar como um solvente orgânico, facilitando muitas reações. Em lugares profundos nos oceanos, as moléculas formadas estariam protegidas da intensa radiação ultravioleta de nosso jovem sol de quatro bilhões de anos atrás. Outro fator que torna este tipo de ambiente atraente para a química de prebiótica é o fato de que conforme nos afastamos da fonte de calor temos gradientes de diferentes temperaturas, que podem facilitar diferentes tipos de reações ${ }^{13}$. Muitas moléculas e biopolímeros foram sintetizados em laboratórios, reproduzindo estes ambientes ainda hoje existentes ${ }^{14}$. Mesmo assim, existem críticos que por diversas razões acreditam que este tipo de ambiente nunca desempenhou um importante papel na Química Prebiótica; uma delas é o fato de que as altas temperaturas destes ambientes não sintetizariam moléculas, mas sim as destruiriam. Outro ponto levantado é que devido às correntes de convecção, os gradientes de temperatura praticamente não existiriam. $\mathrm{O}$ assunto, portanto, é ainda muito debatido na literatura ${ }^{15}$.

Outro tipo de ambiente, que reproduz um efeito diferente do anterior, também tem sido muito estudado. Devido às marés, poças de água do mar ou pequenas lagoas podem ser formadas e devido ao calor do sol as mesmas são secas e, no outro dia, novamente estas poças ou lagoas são cheias. Este ciclo de hidratação e desidratação poderia propiciar a síntese de muitas moléculas e polímeros importantes para a origem da vida ${ }^{16}$

Como vimos, a formação de biopolímeros (peptídeos, proteínas etc) pode ser possível em diversas condições de reação, tais como reação em estado sólido a altas temperaturas, em água super aquecida como ocorre nas fontes geotérmicas no fundo do mar e reações envolvendo ciclos de hidratação e desidratação. No entanto, à temperatura ambiente (por volta de $25^{\circ} \mathrm{C}$ ), em solução aquosa, as reações de formação de biopolímeros não ocorrem espontaneamente. A pergunta que surge é: como os seres vivos sintetizam os biopolímeros? Na verdade os seres vivos utilizam uma espécie de "truque" para a síntese de qualquer substância cuja reação não seja espontânea. Este "truque" é chamado de acoplamento de reações e funciona da seguinte forma: uma reação que ocorre espontaneamente liberando uma quantidade muito grande de energia fica acoplada a uma outra reação que precisa de energia para ocorrer. Os seres vivos utilizam a reação de hidrólise da adenosina trifosfato (ATP) que se transforma em adenosina monofosfato (AMP), liberando uma grande quantidade de energia. Vejamos um esquema desta reação: suponhamos a síntese não espontânea do dímero A-B a partir dos monômeros A-H e B-OH utilizando uma reação acoplada com a degradação de ATP para AMP. Vamos considerar as seguintes reações:

$\mathrm{B}-\mathrm{OH}+\mathrm{ATP} \rightarrow \mathrm{B}-\mathrm{O}-\mathrm{P}-\mathrm{P}+\mathrm{AMP}$

Reação 1

$\mathrm{A}-\mathrm{H}+\mathrm{B}-\mathrm{O}-\mathrm{P}-\mathrm{P} \rightarrow \mathrm{A}-\mathrm{B}+\mathrm{PPi}+\mathrm{H}_{2} \mathrm{O}$

Reação 2

$\mathrm{PPi}+\mathrm{H}_{2} \mathrm{O} \rightarrow 2 \mathrm{Pi}$

Reação 3

A soma das três reações anteriores fornece:

$\mathrm{A}-\mathrm{H}+\mathrm{B}-\mathrm{O}-\mathrm{H}+\mathrm{ATP} \rightarrow \mathrm{A}-\mathrm{B}+\mathrm{AMP}+2 \mathrm{Pi}$

Obviamente que as reações dentro dos seres vivos, para formação dos biopolímeros, são muito mais complexas do que mostrado acima, pois estas reações envolvem enzimas. No entanto, todos os seres vivos que conhecemos utilizam um esquema semelhante ao mostrado acima.

Outro ambiente que não pode ser esquecido é o meio interestrelar no qual já foram detectadas muitas moléculas importantes, contudo, trabalhos nesta área são classificados como Astrobiologia ou Exobiologia (um novo campo da ciência recentemente criado) e não da Química Prebiótica. Essas moléculas detectadas poderiam ser sintetizadas na superfície de meteoros e cometas ou no espaço e, posteriormente, poderiam ser trazidas à Terra pelos mesmos. Estudos têm mostrado que muitas dessas moléculas podem sobreviver a um choque, quando da queda do meteoro ou cometa na Terra, no caso de 
aminoácidos, em experimentos simulando choques de cometas com a Terra, observou-se a formação de ligação peptídica ${ }^{17}$.

Nos parágrafos acima discutimos apenas alguns dos possíveis ambientes que poderiam ter contribuído para o surgimento de vida em nosso planeta. Obviamente a Química Prebiótica não se reduz a somente isto. Existem muitas outras questões importantes para o estudo da origem da vida e fazem parte da Química Prebiótica. Uma delas seria: por que os seres vivos selecionaram somente os aminoácidos da série L e somente os açúcares da série D? Muitos dos experimentos realizados para tentar responder a esta pergunta podem ser considerados pertencentes à Química Prebiótica ${ }^{18}$, porém alguns podem pertencer à Astrobiologia/Exobiologia ${ }^{19}$. A diferença nos dois casos é que a Química Prebiótica simula um ambiente que existiu ou existe na Terra e a Astrobiologia/Exobiologia simula um ambiente fora da Terra. De qualquer maneira, nenhum dos experimentos realizados foi conclusivo e o tema ainda está em aberto. Esse assunto é muito controverso e até o momento não existe uma resposta satisfatória para o problema ${ }^{20}$.

Outros temas também fazem parte da Química Prebiótica. Um deles seria: como foi o primeiro metabolismo? Existem propostas de um metabolismo primitivo baseado em reações fotoquímicas ${ }^{21}$; Wächtershäuser ${ }^{22}$ propôs um modelo baseado na utilização da pirita (FeS) como fonte de elétrons para que reações ocorram em sua superfície. Outra questão: em relação ao código genético, será que tivemos um mundo do $\mathrm{RNA}^{23}$ ou primeiramente tivemos um código genético primitivo baseado em argilas? Uma proposta é a de que moléculas orgânicas poderiam ser adsorvidas na superfície de argilas e com isto as reações ocorreriam sobre essa superfície, quando estas argilas crescessem e se dividissem as informações seriam transferidas ${ }^{24}$. Alguns autores têm proposto o que é chamado de mundo dos lipídios em lugar do mundo do RNA ${ }^{25}$. Como sabemos, as moléculas de lipídios desempenham importantes papéis nos seres vivos atuais ${ }^{26}$ podendo formar facilmente micelas e, no interior destas, teríamos um ambiente separado do mundo exterior para algumas reações ${ }^{25}$. Mais outro tema muito estudado pela Química Prebiótica é o da adsorção de biomoléculas por argilas e areia, que serviriam de pré-concentradores e catalisadores ${ }^{27}$. Em resumo, o que chamamos de Química Prebiótica é um campo de pesquisa muito vasto e não é possível num curto espaço de um artigo discutir todos os aspectos desta área.

Alguém ainda poderia perguntar se a vida foi trazida de outro lugar para o nosso planeta. Esta idéia foi primeiro proposta pelo químico sueco S. Arrhenius; segundo ele, esporos poderiam ter semeado a vida em nosso planeta quando trazidos para cá por ventos solares. Hoje esta teoria é conhecida como panspermia. Existem evidências experimentais de que esporos podem sobreviver à radiação e ao vácuo do espaço ${ }^{28}$. No entanto, a idéia de panspermia simplesmente transfere o problema da origem da vida de nosso planeta para algum outro lugar.

\section{CONCLUSÃO}

A questão de como surgiu a vida em nosso planeta sempre preocupou pessoas interessadas em temas científicos gerais, além de filósofos e cientistas e, através dos tempos, sua abordagem mudou conforme a ciência evoluiu. Entretanto, alguns pontos devem ser destacados.

A teoria da geração espontânea, isto é, o surgimento de seres vivos totalmente formados a partir da matéria inanimada num tempo curto, pode parecer estranha para nós, porém a mesma incentivou diversos pesquisadores a fazerem experimentos e a discutirem o assunto. A teoria foi somente desacreditada pela comunidade científica depois dos experimentos de Pasteur e Tyndall.
Por outro lado, os experimentos de Pasteur e Tyndall, que derrubaram definitivamente com a teoria da geração espontânea, e os estudos de biologia que mostraram a grande complexidade dos seres vivos, criaram na comunidade científica uma sensação de impotência para estudar o problema da origem da vida, visto que os seres vivos são muito complexos.

No entanto, com o passar dos anos, com o desenvolvimento científico, principalmente nos campos da geologia e da astronomia, cientistas começaram a estudar questões, tais como idade e composição química da Terra, estrelas e Sistema Solar, e a propor teorias de como elas surgiram. Estas questões também influenciaram os pesquisadores das áreas biológicas, que começaram a se questionar como surgiu a vida em nosso planeta.

Oparin e, posteriormente, Haldane propuseram um esquema para estudar a questão da origem da vida em nosso planeta. O esquema era baseado no fato de que através de reações químicas entre moléculas simples ocorreria a formação de moléculas cada vez mais complexas e, após milhões de anos, teríamos estruturas tão complexas que poderíamos considerá-las vivas. Miller ao conseguir sintetizar aminoácidos, em um sistema simulando um ambiente primitivo que existiu na Terra, iniciou o que chamamos de Química Prebiótica.

A Química Prebiótica está interessada em qualquer reação química em condições que simule um ambiente que existiu ou exista na Terra e que possa ter contribuído para o surgimento de vida em nosso planeta.

Portanto, o problema da origem da vida é complexo e envolve muitos aspectos, sendo que a Química Prebiótica tem um papel muito importante a desempenhar. Talvez, neste momento, nós os químicos devamos lembrar da frase de S. Berry interpretando uma passagem do livro de C. de Duve "A origem e a evolução da vida na Terra não ocorreu por acaso, mas sim como uma conseqüência das leis da química” ${ }^{29}$.

A ISSOL (International Society for Study of Origin of Life Sociedade Internacional para o Estudo da Origem da Vida) é a sociedade que tem congregado o maior números de pesquisadores, em todo o mundo, interessados nos mais variados aspectos do problema. Em 2002 a ISSOL fará seu congresso trianual, a se realizar de 30 de junho a 5 de julho, em Oaxaca-México. Informações sobre esta sociedade científica e sobre o congresso podem ser encontradas no "site" http://www.biologia.unam.mx/issol/oaxaca.htm.

\section{REFERÊNCIAS}

1. Kenyon, D. H.; Steinman G. D.; Biochemical Predesdination, McGraw: New York, 1969.

2. Ronan, C. A.; História Ilustrada da Ciência da Universidade de Cambridge, Jorge Zahar Editor: Rio de Janeiro, 1987, vols. III e IV.

3. Luisi, P. L.; Origin Life Evol. Biosphere 1998, $28,613$.

4. Orgel, L.; Origin Life Evol. Biosphere 1998, 28, 91.

5. de Andrade Martins, R.; O Universo: Teorias Sobre Sua Origem e Evolução, Editora Moderna: São Paulo, 1994.

6. Bruschi, L. C. A.; A Origem da Vida e o Destino da Matéria, Editora da Universidade Estadual de Londrina: Londrina, 1999.

7. Zaia, D. A. M.; Ciência Hoje 2001, setembro, 20.

8. Miller, S. L.; Science 1953, 117, 528.

9. Delano, J. W.; Origin Life Evol. Biosphere 2001, 31, 311

10. Miyakawa, S.; Murasawa, K.; Kobayashi, K.; Sawaoka, A. B.; Origin Life Evol. Biosphere 2000, 30, 557; Kobayashi, K.; Kaneko, T.; Saito, T.; Oshima, T.; Origin Life Evol. Biosphere 1998, 28, 155; Kobayashi, K.; Tsuchiya, M.; Oshima, T.; Yanagawa, H.; Origin Life Evol. Biosphere 1990, 20, 99; Kobayashi, K.; Hua, L. L.; Hare, P. E.; Hobish, M. K.; Ponnamperuma, C.; Origin Life Evol. Biosphere 1985, 16, 277.

11. Rohlfing, D. L.; McAlhaney, W. W.; Biosystems 1976, 8, 139; Saunders, M. A.; Rohlfing, D. L.; Biosystems 1974, 6, 81.

12. Zaia, D. A. M.; de Santana, H.; Toppan, R.; Zaia, C. T. B. V.; Origin Life Evol. Biosphere 2002 submetido; Mccollom, T. M.; Simoneit, B. R. T.; Origin Life Evol. Biosphere 1999, 29, 167; Albarrán, G.; Collins, K. E.; Collins, C. H.; J. Mol. Evol. 1987, 25, 12. 
13. Rawls, R. L.; Chem. Eng. News 1998, december 21, 35; Holm, N. G.; Origin Life Evol. Biosphere 1992, 22, 5; Holm, N. G.; Origin Life Evol. Biosphere 1990, 20, 93.

14. Ogasawara, H.; Yoshida, A.; Imai, E. I.; Honda, H.; Hatori, K.; Matsuno, K.; Origin Life Evol. Biosphere 2000, 30, 519; Ogata, Y.; Imai, E. I.; Honda, H.; Hatori, K.; Matsuno, K.; Origin Life Evol. Biosphere 2000, 30, 527; Andersson, E.; Holm, N. G.; Origin Life Evol. Biosphere 2000, 30, 9; Imai, E. I.; Honda, H.; Hatori, K.; Matsuno, K.; Origin Life Evol. Biosphere 1999, 29, 249; Mccollom, T. M.; Ritter, G.; Simoneit, B. R. T.; Origin Life Evol. Biosphere 1999, 29, 153; Ingmanson, D. E.; Origin Life Evol. Biosphere 1997, 27, 313.

15. Hennet, R. J. C.; Holm, N. G.; Engel, M. H.; Naturwissenschaften 1992, 79, 361; Corliss, J. B.; Nature 1990, 347, 624; Miller, S. L.; Bada, J. L.; Nature 1989, 337, 23; Nisbet, E. G.; Nature 1989, 337, 23; Miller, S. L.; Bada, J. L.; Friedmann, N.; Origin Life Evol. Biosphere 1989, 19, 536; Corliss, J. B.; Origin Life Evol. Biosphere 1989, 19, 534; Russel, M. J.; Hall, A. J.; Cairns-Smith, A. G.; Braterman, P. S.; Nature 1989, 336, 117; Miller, S. L.; Bada, J. L.; Nature 1988, 334, 609.

16. Nelson, K. E.; Robertson, M. P.; Levy, M.; Miller, S. L.; Origin Life Evol. Biosphere 2001, 31, 221; Bujdák, J.; Rode, B. M.; Origin Life Evol. Biosphere 1999, 29, 451; Rode, B. M.; Son, H. L.; Suwannachot, Y.; Bujdák, J.; Origin Life Evol. Biosphere 1999, 29, 273; Lahav, N.; Nir, S.; Origin Life Evol. Biosphere 1997, 27, 377; Robertson, M. P.; Levy, M.; Miller, S. L.; J. Mol. Evol. 1996, 43, 543; Ito, M.; Handa, N.; Yanagawa, H.; J. Mol. Evol. 1990, 31, 187; Yanagawa, H.; Kojima, K.; Ito, M.; Handa, N.; J. Mol. Evol. 1990, 31, 180; Lawless, J. G.; Levi, N.; J. Mol. Evol. 1979, 13, 286; Lahav, N.; White, D.; Chang, S.; Science 1978, 201, 67.

17. Blank, J. G.; Miller, G. H.; Ahrens, M. J.; Winans, R. E.; Origin Life Evol. Biosphere 2001, 31, 15; Owen, T. C.; Bar-Nun, A.; Origin Life Evol. Biosphere 2001, 31, 435; Whittet, D. C. B.; Gibb, E.L.; Nummelin, A.; Origin Life Evol. Biosphere 2001, 31, 157; Rawls, R. L.; Chem. Eng. News 2001, Mayr 7, 45; Salama, F.; Origin Life Evol. Biosphere 1998, 28, 349; Irvine, W. M.; Origin Life Evol. Biosphere 1998, 28, 365; Cooper, G.W.; Thiemens, M. H.; Jackson, T. L.; Chang, S.; Science 1997, 277, 1072; Chyba, C. F.; Thomas, P. J.; Brooksaw, L.; Sagan, C.; Science 1990, 249, 366; Sakata, A.; Nakagawa, N.; Origin of Life 1978, 51.

18. Viedma, C.; Origin Life Evol. Biosphere 2001, 31, 501; Evegenii, K.; Wolfram, T.; Origin Life Evol. Biosphere 2000, 30, 431; Bonner, W. A.; Origin Life Evol. Biosphere 1999, 29, 317; Bonner, W. A.; Origin Life Evol. Biosphere 1994, 24, 63.
19. Bailey, J.; Origin Life Evol. Biosphere 2000, 31, 167; Mason, S. F.; Origin Life Evol. Biosphere 2000, 30, 435; Bonner, W. A.; Greenberg, J. M.; Rubenstein, E.; Origin Life Evol. Biosphere 1999, 29, 215.

20. Bonner, W. A.; Origin Life Evol. Biosphere 1999, 29, 615.

21. Waddell, T. G.; Bruce, G.K.; Microbiologia SEM 1995, 11, 243.

22. Wächtershäuser, G.; Microbiol. Rev. 1988, 52, 452.

23. Cech, T. R.; Gene 1993, 135, 33.

24. Cairns-Smith, A. G.; Genetic Takeover and the Mineral Origins of Life, Cambridge University Press: Cambridge, 1982

25. Segré, D.; Ben-Eli, D.; Deamer, D. W.; Lancet, D.; Origin Life Evol. Biosphere 2001, 31, 119.

26. Zaia, D. A. M. Em Entendendo a Gordura: Os Ácidos Graxos, Curi, R.; Pompéia, C.; Miyasaka, C. K.; Procópio, J., eds.; Manole: São Paulo, 2002, cap. 1.

27. Zaia, D. A. M.; Vieira, H.; Zaia, C. T. B. V.; J. Braz. Chem. Soc. 2002, 13 679; Pontes-Buarques, M.; Tessis, A.C.; Bonapace, J. A. P.; Monte, M. B. M.; Cortés-Lopez, G.; de Souza-Barros, F.; Vieyra, A.; Origin Life Evol. Biosphere 2001, 31, 343; Wang, K. J.; Ferris, J. P.; Origin Life Evol. Biosphere 2001, 31, 381; Boclair, J. W.; Braterman, P. S.; Brister, B. D.; Jiang, J.; Lou, S.; Wang, Z.; Yarberry, F.; Origin Life Evol. Biosphere 2001, 31, 53; Tessis, A. C.; Penteado-Fava, A.; Pontes-Buarques, M.; de Amorin, H. S.; Bonapace, J. A. P.; de Souza-Barros, F.; Vieyra, A.; Origin Life Evol. Biosphere 1999, 29, 361; Krishnamurthy, R.; Pitsch, S.; Arrhenius, G.; Origin Life Evol. Biosphere 1999, 29, 139; Ertem, G.; Ferris, J. P.; Origin Life Evol. Biosphere 1998, 28, 485; Orgel, L. E.; Origin Life Evol. Biosphere 1998, 28, 227; Hill Jr., A. R.; Böhler, C.; Orgel, L. E.; Origin Life Evol. Biosphere 1998, 28, 235; Liu, R.; Orgel, L. E.; Origin Life Evol. Biosphere 1998, 28, 245; Prabahar, K. J.; Ferris, J. P.; Origin Life Evol. Biosphere 1997, 27, 513.

28. Horneck, G.; Rettberg, P.; Reitz, G.; Wehner, J.; Eschweiler, U.; Strauch, K.; Panitz, C.; Starke, V.; Baumstark-Khan, C.; Origin Life Evol. Biosphere 2001, 31, 527; Clark, B. C.; Baker, A. L.; Cheng, A. F.; Clemett, S. J.; Mckay, D.; Mcsween, H. Y.; Pieters, C. M.; Thomas, P.; Zolensky, M.; Origin Life Evol. Biosphere 1999, 29, 521; Raulin-Cerceau, F.; Maurel, M. C.; Schneider, J.; Origin Life Evol. Biosphere 1998, 28, 597.

29. Berry, S.; J. Chem. Educ. 1997, 74, 950; de Duve, C.; Poeira Vital, Editora Campus: Rio de Janeiro, 1997. 